\title{
Formation of layered proton-conducting zirconium and titanium organophosphonates by topotactic reaction: Physicochemical properties, protons dynamics and atomic-resolution structure
}

\author{
K. Melánová, ${ }^{1}$ J. Brus, ${ }^{1}$ V. Zima, ${ }^{1}$ L. Beneš, ${ }^{2}$ J. Svoboda, ${ }^{3}$ L. Kobera, ${ }^{1}$ P. Kutálek ${ }^{2}$ \\ ${ }^{1}$ Institute of Macromolecular Chemistry, Czech Academy of Sciences, Heyrovsky sq. 2, 16206 Prague 6, Czech \\ Republic \\ 2 Joint Laboratory of Solid State Chemistry, Faculty of Chemical Technology, University of Pardubice, 53210 \\ Pardubice, Czech Republic \\ ${ }^{3}$ Institute of Organic Chemistry and Technology, Faculty of Chemical Technology, University of Pardubice, 53210 \\ Pardubice, Czech Republic
}

Table of Content

Supporting Information SI1 - Experimental parameters to solid-state -NMR Spectroscopy

Supporting information S12 - Results of EDX, elemental and thermogravimetric analyses of the exchanged samples

Supporting Information SI3 - Details to ${ }^{31} \mathrm{P}$ and ${ }^{91} \mathrm{Zr}$ solid-state NMR spectroscopy of $\gamma$-ZrP framework and modified systems

Supporting Information SI4 - Variable-temperature ${ }^{1} \mathrm{H}$ MAS NMR spectroscopy of $\gamma$-ZrP framework 


\section{Supporting Information SI1 - Experimental parameters to solid-state -NMR Spectroscopy}

\section{D and 2D MAS NMR experiments:}

Solid-state NMR spectra were measured using a Bruker Avance 500 WB/US NMR spectrometer (Karlsruhe, Germany, 2013) with 4-mm, 3.2- $\mathrm{mm}$ and 2.5- $\mathrm{mm}$ double-resonance probeheads at Larmor frequencies 500.18, 202.41, 125.783 and $46.478 \mathrm{MHz}$ for ${ }^{1} \mathrm{H},{ }^{31} \mathrm{P},{ }^{13} \mathrm{C}$ and ${ }^{91} \mathrm{Zr}$ nuclei, respectively.

Single-pulse ${ }^{31} \mathbf{P}$ MAS NMR experiments were carried out at $20 \mathrm{kHz}$ magic angle spinning (MAS) with a nutation frequency of $B_{1}\left({ }^{31} \mathrm{P}\right)$ field of $\omega_{1} / 2 \pi=62.5 \mathrm{kHz}$ and a repetition delay of $20 \mathrm{~s}$. The SPINAL-64 ${ }^{1} \mathrm{H}$ decoupling was applied during the signal detection. The applied nutation frequency of $B_{1}\left({ }^{1} \mathrm{H}\right)$ field was $\omega_{1} / 2 \pi=89.3 \mathrm{kHz}$.

The two-dimensional (2D) ${ }^{31} \mathbf{P}$-31P DQ/SQ MAS NMR spectra were measured using the SPC5 recoupling sequence at $17 \mathrm{kHz}$ spinning speed. The number of rotor-synchronized recoupling cycles was varied from 10 to 60 to monitor ${ }^{31} \mathrm{P} . .{ }^{31} \mathrm{P}$ distances. The number of increments in the indirect dimension $F_{1}$ was 160 and the number of scans was 64-128. The ${ }^{31} \mathrm{P}$ shift was calibrated by $\mathrm{CaHPO}_{4}(-0.6 \mathrm{ppm})$.

The 2D ${ }^{1} \mathbf{H}-{ }^{13} \mathbf{C}$ FSLG-HETCOR NMR experiments were performed using the FSLG (Frequency Switched LeeGoldburg) decoupling during the $t_{1}$ evolution period consisting of 64-128 increments each made of $128-440$ scans with a dwell time of $42.6 \mu \mathrm{s}$. Rotation frequency was $\omega_{\mathrm{r}} / 2 \pi=12 \mathrm{kHz}$. The $B_{1}\left({ }^{1} \mathrm{H}\right)$ field strength of FSLG and SPINAL64 decoupling expressed in frequency units $\omega_{1} / 2 \pi=\gamma B_{1}$ was $89.3 \mathrm{kHz}$.

The 2D ${ }^{1} \mathbf{H}-{ }^{1} \mathbf{H}$ EXSY NMR experiments using the standard NOESY-type three-pulse sequence were carried out at 28 $\mathrm{kHz}$ MAS with a nutation frequency of $B_{1}\left({ }^{1} \mathrm{H}\right)$ field of $\omega_{1} / 2 \pi=89.3 \mathrm{kHz}$ and a repetition delay of $4 \mathrm{~s}$. The evolution period consisted of 64 increments each made of 8 scans with a dwell time of $35.7 \mu$ s. The spin-exchange period varied from 0.1 to $100 \mathrm{~ms}$ and the temperate was set to 300 and $330 \mathrm{~K}$.

The ${ }^{91}$ Zr WURST-QCPMG NMR experiment was carried out using a $50 \mu \mathrm{C}$ CT-selective WURST pulse and $500 \mathrm{kHz}$ sweep width, with 64 loops. All ${ }^{91} \mathrm{Zr}$ ssNMR spectra were collected as onepiece-spectrum at offset $\mathrm{O}_{1}=-20 \mathrm{kHz}$ and the recycle delay of $1 \mathrm{~s}$. For each spectrum $20 \mathrm{k}-100 \mathrm{k}$ transients were collected with $1 / \tau_{\mathrm{a}}=2500 \mathrm{~Hz}$. All samples were packed into a 4-mm Teflon tubes to avoid the $\mathrm{Zr}$ background signal. ${ }^{91} \mathrm{Zr}$ chemical shifts were referenced to a concentrated solution of $\mathrm{Cp}_{2} \mathrm{ZrCl}_{2}$ in $\mathrm{CH}_{2} \mathrm{Cl}_{2}\left(\delta_{\text {iso }}=0.0 \mathrm{ppm}\right)$. High-power ${ }^{1} \mathrm{H}$ decoupling $(\mathrm{CW})$ was used to eliminate heteronuclear dipolar couplings. All NMR spectra were processed using the Top Spin 3.5 pl2 software package as well as fitting of $y$-ZrP spectral lines. 
Supporting information S12 - Results of EDX, elemental and thermogravimetric analyses of the exchanged samples

Table S1. Results of EDX, elemental and thermogravimetric analyses of the exchanged samples. The content of C, $H$, $\mathrm{N}, \mathrm{S}$ and weight losses calculated from formulas given in Table 1 are in parenthesis.

\begin{tabular}{|l|c|c|c|c|c|c|c|c|}
\hline \multirow{2}{*}{ Denotation } & Molar ratio & \multicolumn{4}{|c|}{ Elemental analysis } & \multicolumn{2}{c|}{ Weight loss \% } \\
\cline { 2 - 9 } & $\mathrm{P} / \mathrm{Zr}$ & $\mathrm{S} / \mathrm{Zr}$ & $\mathrm{C} \%$ & $\mathrm{H} \%$ & $\mathrm{~N} \%$ & $\mathrm{~S} \%$ & first & total \\
\hline Zr-A & 2.09 & 0.20 & 2.30 & 1.86 & 0.99 & 1.16 & 8.4 & 19.8 \\
& & & $(2.20)$ & $(1.86)$ & $(0.64)$ & $(1.47)$ & $(8.24)$ & $(19.10)$ \\
\hline Zr-B & 1.98 & 0.35 & 4.58 & 1.91 & 1.52 & 2.93 & 7.1 & 24.6 \\
& & & $(4.67)$ & $(2.13)$ & $(1.36)$ & $(3.12)$ & $(7.72)$ & $(24.24)$ \\
\hline Zr-C & 2.03 & 0.47 & 5.95 & 2.20 & 1.76 & 3.91 & 8.0 & 28.6 \\
& & & $(5.91)$ & $(2.30)$ & $(1.72)$ & $(3.95)$ & $(8.13)$ & $(27.48)$ \\
\hline Ti-B & 2.06 & 0.39 & 6.24 & 2.29 & 1.79 & 3.80 & 7.0 & 30.0 \\
& & & $(6.20)$ & $(2.40)$ & $(1.81)$ & $(4.14)$ & $(7.55)$ & $(28.48)$ \\
\hline Ti-C & 2.02 & 0.42 & 6.81 & 2.21 & 1.96 & 4.20 & 8.0 & 30.1 \\
& & & $(6.38)$ & $(2.53)$ & $(1.86)$ & $(4.26)$ & $(8.55)$ & $(29.82)$ \\
\hline Ti-D & 2.07 & 0.41 & 6.44 & 2.35 & 1.89 & 3.87 & 8.1 & 29.8 \\
& & & $(6.26)$ & $(2.52)$ & $(1.82)$ & $(4.18)$ & $(8.58)$ & $(29.56)$ \\
\hline
\end{tabular}




\section{Supporting Information SI3 - Details to ${ }^{31} \mathrm{P}$ and ${ }^{91} \mathrm{Zr}$ solid-state NMR spectroscopy of $\gamma$-ZrP framework and modified systems}

As demonstrated in Figure S1a, the ${ }^{31} \mathrm{P}$ MAS NMR spectrum of initial ZrP system is dominated by the two narrow signals at -9.8 and $-27.4 \mathrm{ppm}$. These signals reflect the framework phosphate groups $\mathrm{P}(\mathrm{OZr})_{4}$, and interlayer phosphate units $\mathrm{P}(\mathrm{OZr})_{2}(\mathrm{OH})_{2}$. The arrangement of these units in ZrP framework can be deduced from 2D ${ }^{31} \mathrm{P}_{-}{ }^{31} \mathrm{P}$ $\mathrm{DQ} / \mathrm{SQ}$ MAS NMR spectrum measured at long recoupling periods (30-60 recoupling cycles) which allow monitoring the long-range ${ }^{31} \mathrm{P} . . .{ }^{31} \mathrm{P}$ interatomic distances up to ca. 5-6 $\AA$ (Figure S2a). As reflected by the full set of ${ }^{31} \mathrm{P} . . .{ }^{31} \mathrm{P}$ correlation signals, the main phosphorous species in the ZrP system are mutually interconnected, and the average ${ }^{31} \mathrm{P} \ldots{ }^{31} \mathrm{P}$ interatomic distance in $\mathrm{P}(\mathrm{OZr})_{4} \ldots \mathrm{P}(\mathrm{OZr})_{4}, \mathrm{P}(\mathrm{OZr})_{2}(\mathrm{OH})_{2} \ldots \mathrm{P}(\mathrm{OZr})_{2}(\mathrm{OH})_{2}$ and $\mathrm{P}(\mathrm{OZr})_{4} \ldots \mathrm{P}(\mathrm{OZr})_{2}(\mathrm{OH})_{2} \quad \mathrm{pairs}$ is shorter than 5-6 A. This arrangement is typical for incorporation of $\mathrm{P}(\mathrm{OZr})_{4}$ framework $\mathrm{species}$ and $\mathrm{P}(\mathrm{OZr})_{2}(\mathrm{OH})_{2}$ interlayer groups into the crystal lattice of $\gamma$-ZrP framework.

The main signals of the $\gamma$-ZrP framework are further accompanied by the low intensity signals at ca. -13 and -20 ppm, which reflect presence of some impurities and/or structural defects. In this regard, we found out that the phosphorous species resonating at $-13 \mathrm{ppm}$ exhibit fast $T_{1}\left({ }^{31} \mathrm{P}\right)$ longitudinal relaxation indicating their high local mobility. This fact together with the absence of this resonance in the 2D ${ }^{31} \mathrm{P}-{ }^{31} \mathrm{P} D Q / S Q$ MAS NMR correlation spectrum (Figure S2a) indicates that these species are only weakly coupled to the $\gamma$-ZrP framework.

In contrast, the signals at ca. -19 and -20 ppm show well-evolved auto-correlation signals at resonance frequencies around $(-20) \times(-40) \mathrm{ppm}$ indicating their rigidity and spatial proximity. Based on literature data, ${ }^{1}$ these signals can be assigned to the fragments adopting the framework structure of $\alpha$-ZrP modification. As no correlations were found between the $\gamma$-ZrP framework and these $\alpha$-ZrP fragments, we expect that the $\alpha$-ZrP fragments form a secondary phase-separated fraction.

The presence of two modifications of ZrP framework is confirmed by ${ }^{91} \mathrm{Zr}$ WURST-QCPMG NMR spectra where two ${ }^{91} \mathrm{Zr}$ NMR lines are resolved (Figure S3a). The extracted NMR parameters (isotropic chemical shifts, $\delta_{\text {iso }}\left({ }^{91} \mathrm{Zr}\right.$ ), and quadrupolar coupling constants, $\left.C_{Q}\right)$ clearly confirm the presence of $\gamma-Z r P$ modification $\left(\delta_{\text {iso }}\left({ }^{91} \mathrm{Zr}\right)=-80 \mathrm{ppm}\right.$ and $\mathrm{C}_{Q}$ $=9.1 \mathrm{MHz})$, and a low amount of the $\alpha-\mathrm{ZrP}$ phase $\left(\delta_{\text {iso }}\left({ }^{91} \mathrm{Zr}\right)=90 \mathrm{ppm}\right.$ and $\left.\mathrm{C}_{\mathrm{Q}}=6 \mathrm{MHz}\right)$. All the obtained parameters are summarized in Table S2.

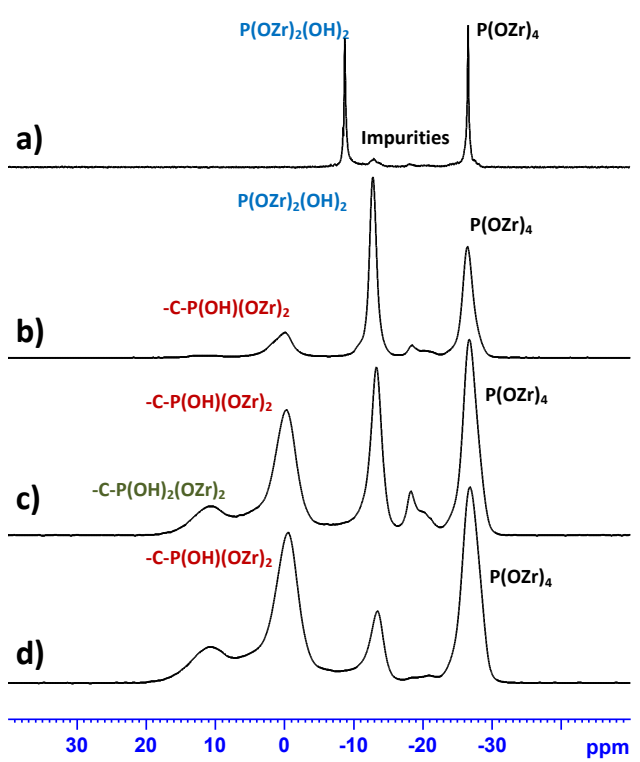

Figure S1. ${ }^{31}$ P MAS NMR spectra of initial $\gamma$-ZrP system (a), and modified ZrP substrates Zr-A (b), Zr-B (c) and Zr-C (d). 

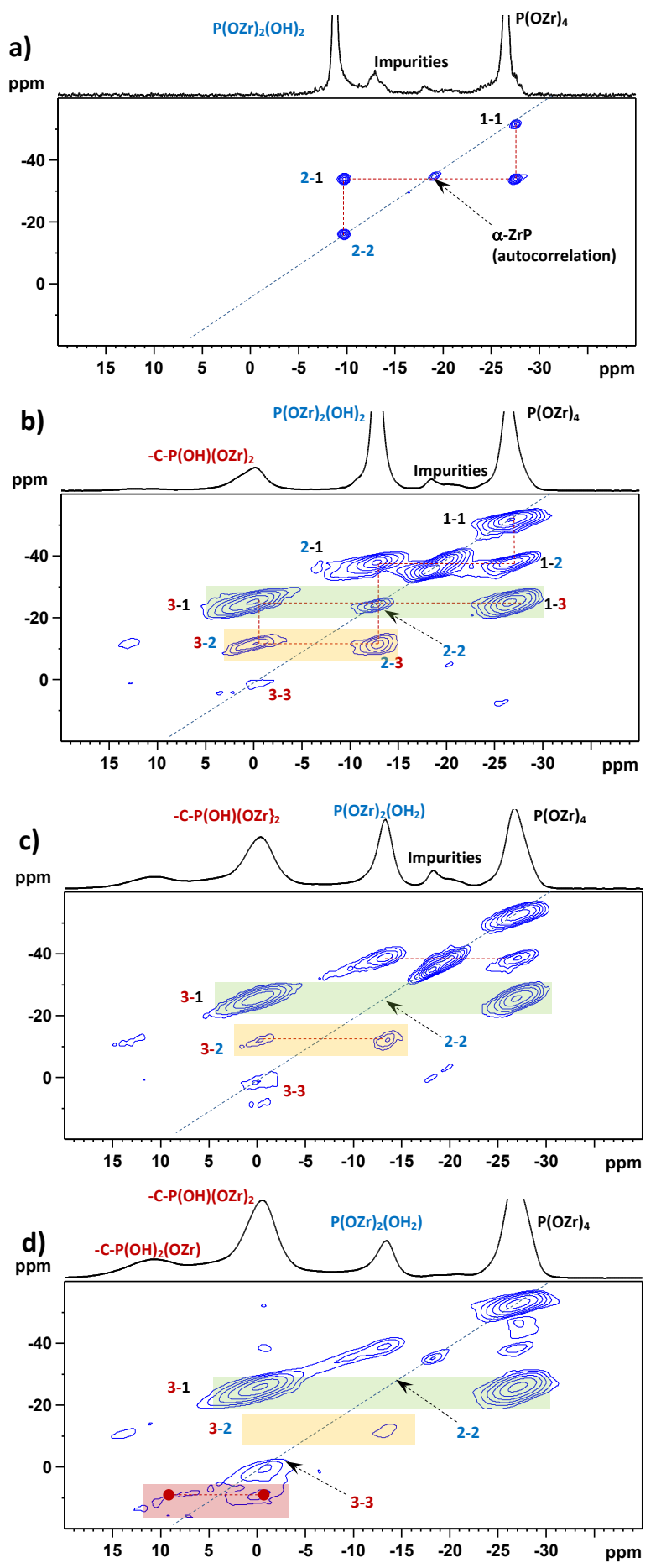

Figure S2. ${ }^{31} \mathrm{P}-{ }^{31} \mathrm{P}$ SQ/DQ MAS NMR spectra of initial $\gamma$-ZrP system (a), and modified ZrP substrates Zr-A (b), Zr-B (c) and Zr-C (d). 

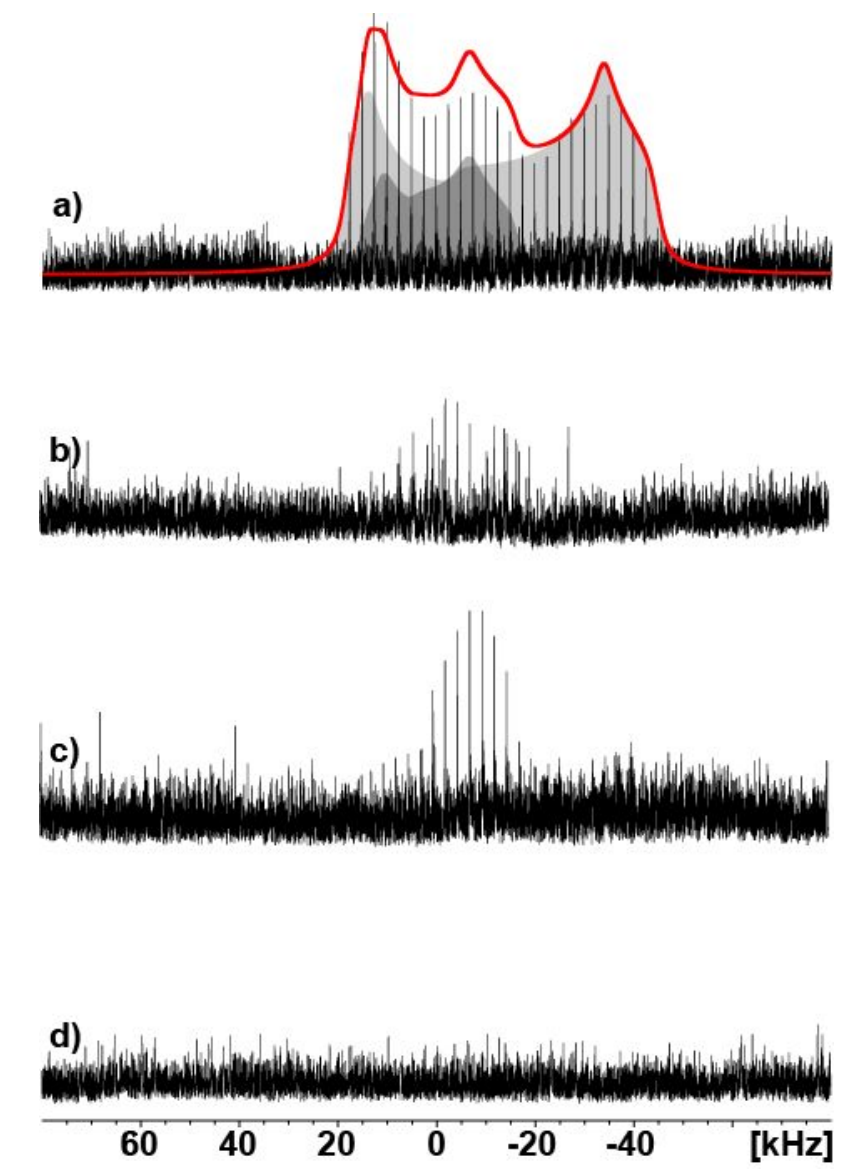

Figure S3. Experimental ${ }^{91} \mathrm{Zr}$ WURST-QCPMG NMR spectra of the parent $\gamma$-ZrP system (a), and modified ZrP substrates Zr-A (b), $\mathrm{Zr}-\mathrm{B}$ (c) and $\mathrm{Zr}-\mathrm{B}(\mathrm{d})$.

Table S2. Observed Parameters for ${ }^{91} \mathrm{Zr}$ Chemical Shift and Quadrupole Coupling Tensors in Layered ZrP Materials

\begin{tabular}{lllllllll}
\hline Signal & $\begin{array}{l}{ }^{91} \mathrm{Zr} \delta_{\text {iso }} \\
(\mathrm{ppm})\end{array}$ & $\begin{array}{l}\mathrm{C}_{\mathrm{Q}} \\
(\mathrm{MHz})\end{array}$ & $\eta_{\mathrm{Q}}$ & $\begin{array}{l}\Omega \\
(\mathrm{ppm})\end{array}$ & $\kappa$ & $\begin{array}{l}\alpha \\
(\mathrm{deg})\end{array}$ & $\begin{array}{l}\beta \\
(\mathrm{deg})\end{array}$ & $\begin{array}{l}\gamma \\
(\mathrm{deg})\end{array}$ \\
\hline Light* & -80 & 9.1 & 0.15 & 20 & 0.5 & 30 & 50 & 0 \\
Dark* & 90 & 6.0 & 0.3 & 12 & 0.2 & 80 & 50 & 5 \\
\hline
\end{tabular}

* The NMR parameters of $\alpha$-ZrP and $\gamma$-ZrP were adapted from literature ref.2, except $\left.\delta_{\text {iso }}{ }^{(91} \mathrm{Zr}\right)$ of $\alpha$-ZrP. 
Supporting Information SI4 - Variable-temperature ${ }^{1} \mathrm{H}$ MAS NMR spectroscopy of $\gamma$-ZrP framework

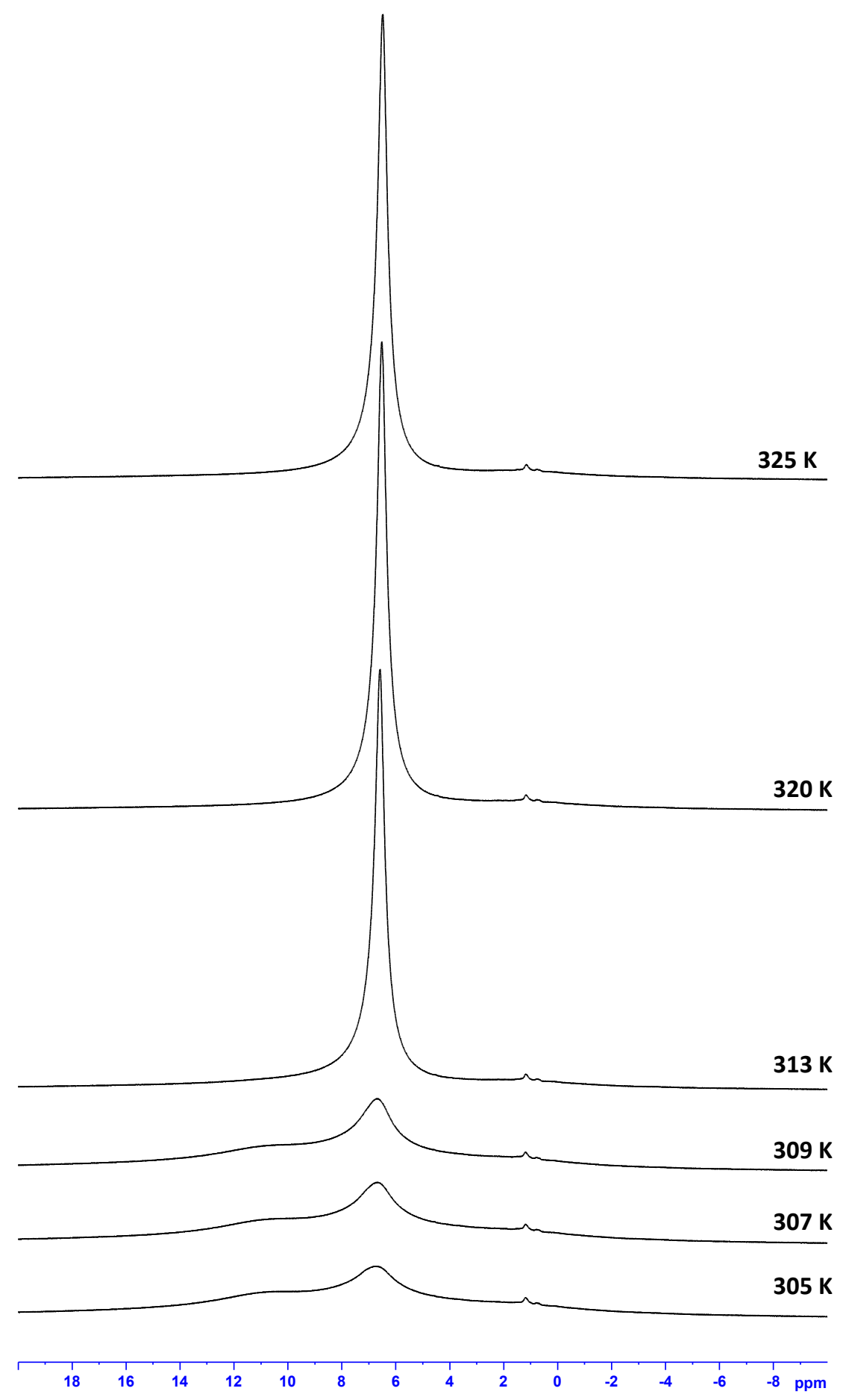

Figure S4. Variable-temperature ${ }^{1} \mathrm{H}$ MAS NMR spectroscopy of $\gamma$-ZrP framework. 


\section{References}

1. 1. Pica, M.; Donnadio, A.; Troni, E.; Capitani, D.; Casciola, M. Looking for New Hybrid Polymer Fillers: Synthesis of Nanosized $\alpha$-Type $\mathrm{Zr}$ (IV) Organophosphonates through an Unconventional Topotactic Anion Exchange Reaction Inorg. Chem. 2013, 52, 7680-7687.

2. Yan, Z.; Kirby, C. W.; Huang, Y. Directly Probing the Metal Center Environment in Layered Zirconium Phosphates by Solid-State ${ }^{91}$ Zr NMR J. Phys. Chem. C, 2008, 112 (23), pp 8575-8586 